\title{
Effect of granular activated carbon addition on the effluent properties and fouling potentials of membrane-coupled expanded granular sludge bed process
}

\author{
An Ding ${ }^{a}$, Heng Liang ${ }^{\mathrm{a}, *}$, Fangshu $\mathrm{Qu}^{\mathrm{a}}$, Langming Bai ${ }^{\mathrm{a}}$, Guibai $\mathrm{Li}^{\mathrm{a}}$, Huu Hao Ngo ${ }^{\mathrm{b}}$, Wenshan Guo ${ }^{\mathrm{b}}$ \\ ${ }^{a}$ State Key Laboratory of Urban Water Resource and Environment, Harbin Institute of Technology, 73 Huanghe Road, Nangang District, Harbin 150090, PR China \\ ${ }^{\mathrm{b}}$ Faculty of Engineering, University of Technology, P.O. Box 123, Broadway, Sydney, NSW 2007, Australia
}

\section{H I G H L I G H T S}

- Adding GAC alleviated membrane fouling of a membrane-coupled EGSB process.

- It reduced the concentrations of SMP, $\mathrm{SMP}_{\mathrm{ps}}$ and $\mathrm{SMP}_{\mathrm{pr}}$ by $26.8 \%, 27.8 \%$ and $24.7 \%$.

- It primarily reduced tryptophan proteins, aromatic proteins and fulvic substances.

- GAC addition mainly decreased the cake layer resistance proportion by $53.5 \%$.

\section{A R T I C L E I N F O}

\section{Article history:}

Received 15 July 2014

Received in revised form 14 August 2014

Accepted 17 August 2014

Available online 23 August 2014

\section{Keywords:}

Membrane-coupled anaerobic process

Membrane fouling

Granular activated carbon

Membrane resistance

Soluble microbial products

\begin{abstract}
A B S T R A C T
To mitigate membrane fouling of membrane-coupled anaerobic process, granular activated carbon (GAC: $50 \mathrm{~g} / \mathrm{L}$ ) was added into an expanded granular sludge bed (EGSB). A short-term ultrafiltration test was investigated for analyzing membrane fouling potential and underlying fouling mechanisms. The results showed that adding GAC into the EGSB not only improved the COD removal efficiency, but also alleviated membrane fouling efficiently because GAC could help to reduce soluble microbial products, polysaccharides and proteins by $26.8 \%, 27.8 \%$ and $24.7 \%$, respectively, compared with the control system. Furthermore, excitation emission matrix (EEM) fluorescence spectroscopy analysis revealed that GAC addition mainly reduced tryptophan protein-like, aromatic protein-like and fulvic-like substances. In addition, the resistance distribution analysis demonstrated that adding GAC primarily decreased the cake layer resistance by 53.5\%. The classic filtration mode analysis showed that cake filtration was the major fouling mechanism for membrane-coupled EGSB process regardless of the GAC addition.
\end{abstract}

(c) 2014 Elsevier Ltd. All rights reserved.

\section{Introduction}

Due to the importance of energy recovery and resources recycling, anaerobic membrane bioreactor (AnMBR) and membrane coupled anaerobic processes have become more and more promising technologies for wastewater treatment in recent years (Stuckey, 2012). Although AnMBR has advantages such as high removal efficiency of organic matters and small footprint, etc., there are still some challenging issues. Particularly, membrane fouling is the key challenge for the widespread applications of AnMBR (Guo et al., 2012; Meng et al., 2009).

It is reported that soluble microbial products (SMP) or loosely bound extracellular polymeric substances (EPS), which are pro-

\footnotetext{
* Corresponding author. Tel./fax: +86 45186283001.

E-mail address: hitliangheng@163.com (H. Liang).
}

duced from cell metabolism and lysis, play an important role in membrane fouling (Lin et al., 2009; Wang et al., 2014). Barker and Stuckey (1999) have reviewed the advanced treatments such as activated carbon, synthetic resin adsorption, ozonation, oxidation, coagulation and breakpoint chlorination for reducing SMP. Among all the options, granular activated carbon (GAC) is the most effective method for the removal of SMP.

As GAC has high removal efficiency of SMP than others (powdered activated carbon, synthetic resin, etc.) (Barker and Stuckey, 1999), several researchers investigated the GAC addition in the membrane bioreactor (MBR) system to alleviate membrane fouling. Johir et al. have reported that the addition of GAC as a suspended medium in a submerged membrane bioreactor (SMBR) achieved high organic removal (95\%) as well as reduced transmembrane pressure (TMP) development by $58 \%$, as GAC addition eliminated the organic molecules in SMP with molecular weight of 
1200-150 Dalton (Da) (Johir et al., 2011, 2013). Kim et al. (2010) have also found that GAC addition into an anaerobic fluidized bed membrane bioreactor could reduce membrane fouling rate efficiently.

To date, few studies have explained the mechanisms or given the reasons of GAC alleviating membrane fouling in membranecoupled anaerobic reactors. Thus, it is necessary to know which kinds of organic matters are easily absorbed and removed by GAC addition and how GAC affect the filtration resistance distribution in membrane-coupled anaerobic reactors system. In this study, the effect of GAC addition on the performance of an expanded granular sludge bed (EGSB) was investigated. The properties of effluents were characterized. The short-term experiments on membrane fouling potentials and mechanisms were carried out in a dead-end ultrafiltration (UF) setup.

\section{Methods}

\subsection{EGSB setup}

As shown in Supplementary data, the performance of two labscale EGSBs (EGSB1 and EGSB2) fed with synthetic wastewater were examined in parallel during 3 month operation. GAC with the concentration of $50 \mathrm{~g} / \mathrm{L}$ was added into EGSB1 at the beginning of the operation. The GAC concentration was chosen based on the study of Kim et al. (2010). EGSB2 was a control system without GAC addition. The effective working volume of each EGSB was $3 \mathrm{~L}$ (diameter of $50 \mathrm{~mm}$ and length of $1800 \mathrm{~mm}$ ), and the effluent flow rate was set at $0.75 \mathrm{~L} / \mathrm{h}$, corresponding to a hydraulic retention time (HRT) of $4 \mathrm{~h}$. Some portion of mixed liquor on the top was recycled back to the reactor with a liquid upflow velocity of $10 \mathrm{~m} / \mathrm{h}$. Both of the reactors were inoculated with $10 \mathrm{~g} / \mathrm{L}$ granular sludge (with the average particle size of $940 \mu \mathrm{m}$ ) originating from a large-scale upflow anaerobic sludge blanket of a soybean wastewater treatment plant in Harbin, China. The granular sludge was washed using deionized (DI) water for 3 times before inoculation.

In order to simulate the domestic sewage, the synthetic wastewater consisted of glucose (200 mg/L), sodium acetate $(150 \mathrm{mg} / \mathrm{L})$, $\mathrm{NH}_{4} \mathrm{Cl}(150 \mathrm{mg} / \mathrm{L}), \mathrm{KH}_{2} \mathrm{PO}_{4}(22 \mathrm{mg} / \mathrm{L}), \mathrm{NaHCO}_{3}(400 \mathrm{mg} / \mathrm{L})$, and a mixture of trace elements. The feed solution contained 310$360 \mathrm{mg} / \mathrm{L}$ of chemical oxygen demand (COD), $35-45 \mathrm{mg} / \mathrm{L}$ of $\mathrm{NH}_{4}^{+}-\mathrm{N}, 4-5 \mathrm{mg} / \mathrm{L}$ of $\mathrm{TP}$, and $\mathrm{pH}$ value of 7.0-7.5.

\subsection{Adsorbents and static adsorption tests}

The GAC was made of coconut shell from Tianjin Binhai Kody Company. The particle size of GAC was between 500 and $1700 \mu \mathrm{m}$ (screen mesh: 10-30 meshes). It had a BET surface area of $867 \pm 10 \mathrm{~m}^{2} / \mathrm{g}$.

GAC were washed with DI water for several times until the COD of the supernatant was less than $5 \mathrm{mg} / \mathrm{L}$ (limit of detection) before used. GAC static adsorption experiment was carried out in a $1 \mathrm{~L}$ baker with magnetic stirrer. GAC with the mass concentration of $50 \mathrm{~g} / \mathrm{L}$ was added in the baker. The solution stirred at $150 \mathrm{rpm}$ and $25^{\circ} \mathrm{C}$ for $24 \mathrm{~h}$. The supernatant samples were taken out for COD analysis at $0 \mathrm{~h}, 2 \mathrm{~h}, 4 \mathrm{~h}, 12 \mathrm{~h}$ and $24 \mathrm{~h}$, respectively.

\subsection{Short-term UF tests}

Bench scale short-term dead-end ultrafiltration (UF) tests were carried out to study the membrane fouling potential of the EGSB effluents during 75-80 days. The effluents samples were collected from the outlets of EGSB1 and EGSB2 (Sample 1 from EGSB1: S1; Sample 2 from EGSB2: S2) for the short-term UF tests. Each UF test was carried out in triplicates.
The filtration system consisted of a nitrogen gas cylinder, an UF cell and an electric balance and a computer (Supplementary data). Flat sheet polyethersulfone (PES) UF membranes (MWCO $100 \mathrm{kDa}$, OM100076, Pall, USA) with an effective surface area of $43.01 \mathrm{~cm}^{2}$ were used. The volume of the UF cell (Amicon 8400, Millipore, USA) was $350 \mathrm{~mL}$ without stirring. The membrane was placed at the bottom of the cell with glossy side towards the bulk solution. Nitrogen gas was used to drive the feed solution through the membrane at a constant pressure of $30 \mathrm{kPa}$. The filtrate flowed into a $500 \mathrm{~mL}$ beaker on the electronic balance which was connected to a computer. The weighting data were automatically logged every $5 \mathrm{~s}$.

\subsection{Membrane resistance model}

To evaluate fouling behaviors of the membrane, Darcy's law was applied to estimate the total fouling resistances as shown in Eq. (1):

$R_{t}=\frac{\Delta P}{\mu J}$

where $J$ is the final permeate flux, $\Delta P$ is trans-membrane pressure, $\mu$ is dynamic viscosity, and $R$ denotes the resistance:

$R_{t}=R_{m}+R_{c p}+R_{p}+R_{c}$

$R_{m}=\frac{\Delta P}{\mu J_{0}}$

$R_{c p}=R_{t}-\frac{\Delta P}{\mu J_{1}}$

$R_{c}=\frac{\Delta P}{\mu J_{1}}-\frac{\Delta P}{\mu J_{2}}$

As shown in Eq. (2), $R_{t}, R_{m}, R_{c p}, R_{p}$ and $R_{c}$ are total, membrane, concentration polarization layer, pore blocking and cake layer resistances, respectively (Li and Wang, 2006). $R_{m}$ is determined by filtering the DI water through the clean membrane; $J_{0}$ is the permeate flux of DI water filtered through the clean membrane (from Eq. (3)); $R_{c p}$ is calculated by filtering the DI water through the fouled membrane; and $J_{1}$ is the final permeate flux (from Eq. (4)). $R_{c}$ is determined from the difference in resistance before and after gentle membrane cleaning to remove the cake layer using a sponge, and $J_{2}$ is the later flux (from Eq. (5)).

\subsection{Modeling for membrane fouling process}

The flux decline of UF in the dead-end cell under constant pressure could be described by different blocking mechanisms: complete blocking, standard blocking, intermediate blocking and cake filtration (Shen et al., 2010). The equations for different membrane blocking mechanisms are listed below: (1) Complete blocking: $-J+J_{0}=a V$; (2) Standard blocking: $1 / t+b=J_{0} / V$; (3) Intermediate blocking: $-\ln J+\ln J_{0}=c V$; (4) Cake filtration: $1 / J-1 / J_{0}=d V$, where $V$ is the volume of the feed water; $a, b, c$ and $d$ are all constants.

\subsection{Analytical methods}

COD was measured according to Standard Methods (CEPB, 2002). Turbidity was determined by the Turbidity Meter (HI98713-02 ISO, HANNA, US). Ultraviolet absorbance at $254 \mathrm{~nm}$ $\left(\mathrm{UV}_{254}\right)$ was determined by a spectrophotometry (SPECORD 50 PLUS, Germany). Particle size distribution was measured using MasterSizer Laser Diffraction Particle Size Analyzer (MasterSizer 2000, Malvern Instruments, England). The SMP was obtained by measuring the dissolved total organic carbon (TOC) in the effluents. The effluent sample was centrifuged at $4000 \mathrm{rpm}$ for $10 \mathrm{~min}$, and then filtered through a $0.45 \mu \mathrm{m}$ membrane. TOC concentration 
was evaluated using a TOC analyzer (multi N/C 2100S, Analytic Jena, Germany). The concentrations of protein in SMP $\left(\mathrm{SMP}_{\mathrm{pr}}\right)$ were measured by the Lowry method (Lowry et al., 1951). The concentrations of polysaccharide in SMP $\left(\mathrm{SMP}_{\mathrm{ps}}\right)$ were determined by the phenolsulfuric method (DuBois et al., 1956). The analyses were all conducted in duplicates, and their average values were reported.

The fluorescence excitation-emission (EEM) spectrometry was used for obtaining the information of the SMP, and the details could be found in Meng's paper (Meng et al., 2011). Excitation spectrum and emission spectrum was scanned from $220-450 \mathrm{~nm}$ at $5 \mathrm{~nm}$ increments and $250-550 \mathrm{~nm}$ at $5 \mathrm{~nm}$ increments, respectively.

\section{Results and discussion}

\subsection{Effect of GAC addition on the COD removal performance of the EGSB}

The results show that the COD removal by GAC static adsorption was $22 \%$ (removal of $77 \mathrm{mg}$ COD/L) after 2 h reaction, and kept stable at around $25 \%$ (removal of $90 \mathrm{mg} \mathrm{COD} / \mathrm{L}$ ) for the next $10 \mathrm{~h}$ (Supplementary data). This indicates that GAC could absorb part of the COD in the influent, and the adsorption capacity of the GAC for this feed water was $6.67 \mathrm{mg}$ COD/g GAC. As seen in Supplementary data, the COD concentration of EGSB1 effluent (S1) dropped more sharply than that of EGSB2 effluent (S2) at the first 10 days and decreased slightly in the next 20 days. After that, S1 and S2 were stable with the concentrations of $50-60 \mathrm{mg} / \mathrm{L}$ and 90-100 mg/L, respectively. The results showed that GAC could perform well in EGSB for COD removal efficiencies with the value of $80 \%$ (higher than that of $62 \%$ in the control system). After 60 days, there were slight fluctuations in both $\mathrm{S} 1$ and $\mathrm{S} 2$ due to the temperature change (between 15 and $30^{\circ} \mathrm{C}$ ). The COD removal efficiency increased with increasing the temperature. The results are in line with the report of Gao et al. (2014). From the static adsorption tests, GAC adsorption saturation reached after 4-8 h, however, the EGSB with GAC addition still kept higher COD removal performance after 3 month operation. It is known that the COD removal depended on the GAC adsorption and anaerobic granular sludge biodegradation in EGSB1 system. The reason for this phenomenon was that GAC addition not only adsorbed partial COD, but might enhance the activity of the anaerobic granular sludge as well. Ozgun et al. (2013) review that the specific methanogenic activity of the sludge can be improved by activated carbon addition in the AnMBR because the support surface provided by activated carbon in order to protect the biomass from high shear conditions. Similarly, Johir et al. (2013) also found that GAC addition improved the COD removal from $89.2 \%$ to $95.6 \%$ in a aerobic MBR system during the synthetic wastewater treatment. The reason that the efficiencies were higher than ours might be the membrane-based treatment. Therefore, conclusion can be drawn that EGSB with GAC addition could improve the COD removal efficiency due to the adsorption and anaerobic sludge activity improvement.

\subsection{Effect of GAC addition on the characteristics of the effluents}

Effluents from EGSB1 and EGSB2 were taken out for analysis during Day 75-80. Table 1 presents the characteristics of the effluent samples (named S1 and S2) for both EGSB1 and EGSB2. GAC addition could only reduce the effluent turbidity by $6.8 \%$ compared to the control, which indicated that GAC is not able to remove the colloids and large size particles from the effluent significantly. Thus, suspended solid is still a problem to deal with in the EGSB system. Moreover, GAC addition helped to reduce the value of $U_{254}$ which represented the organic matters containing the functional groups such as $\mathrm{C}=\mathrm{C}$ and $\mathrm{C}=\mathrm{O}$. Furthermore, in comparison with $\mathrm{S} 2$, the concentrations of SMP, $\mathrm{SMP}_{\mathrm{ps}}$ and $\mathrm{SMP}_{\mathrm{pr}}$ in $\mathrm{S} 1$ were $11.7 \pm 0.3,2.6 \pm 0.1$ and $7.9 \pm 1.2 \mathrm{mg} / \mathrm{L}$, which reduced by $26.8 \%, 27.8 \%$ and $24.7 \%$, respectively. The results are in line with the review of Barker and Stuckey (1999), who stated that GAC was the most effective method for SMP removal in the aerobic activated sludge system. From the results above, it can be concluded that GAC could also help to reduce the dissolved polysaccharides and proteins in the anaerobic reactor.

Fig. 1 illustrates the particle size distribution of the effluents and Table 2 gives the detail of the data. The average particle size increased a little bit (22.6\%) after adding GAC during 3 month operation. Normally, in aerobic system such as submerged MBR, adding a certain amount of carriers might break up sludge flocs and cause an increase in the amount of small particles and supernatant total organic carbon, accelerating membrane fouling (Huang et al., 2008; Wei et al., 2006). However, in anaerobic system such as EGSB system, granule formation is strongly influenced by the upflow liquid velocity and HRT. Hence, a short HRT combined with a high upflow liquid velocity could increase the density of the granular (Liu and Tay, 2004; Tiwari et al., 2006). Meanwhile, adding GAC could enhance the biofilm attachment. Therefore, the addition of GAC increased the average particle size in the effluent.

It has been reported that SMP are complex and play an important role in membrane fouling (Meng et al., 2009). However, it is not clear that which types of proteins and polysaccharides were the main foulants and whether the GAC influences their existence in anaerobic reactors. Therefore, fluorescence excitation-emission spectrometry (EEM) was used to better understand the influence of GAC addition on the components of SMP. The fluorescence spectra data are illustrated in Fig. 2 and the peak values are summarized in Table 3. There were 4 main peaks identified from the fluorescence spectra of SMP samples through the literatures. The first main peak was observed at excitation/emission wavelengths

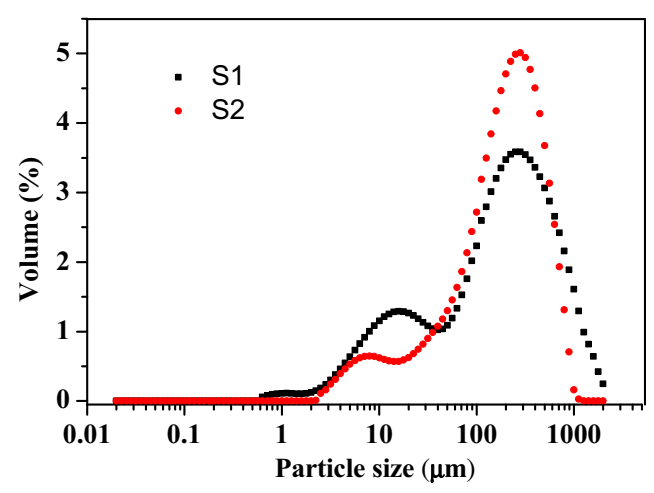

Fig. 1. Particle size distributions of EGSB effluents.

Table 1

The characteristics of the effluent samples.

\begin{tabular}{|c|c|c|c|c|c|}
\hline Effluent samples & Turbidity (NTU) & $\mathrm{UV}_{254}$ & $\mathrm{SMP}(\mathrm{mg} / \mathrm{L})$ & $\mathrm{SMP}_{\mathrm{ps}}(\mathrm{mg} / \mathrm{L})$ & $\mathrm{SMP}_{\mathrm{pr}}(\mathrm{mg} / \mathrm{L})$ \\
\hline S1 & $37.2 \pm 2.3$ & $0.048 \pm 0.001$ & $11.7 \pm 0.3$ & $2.6 \pm 0.1$ & $7.9 \pm 1.2$ \\
\hline S2 & $39.7 \pm 1.1$ & $0.067 \pm 0.000$ & $16.0 \pm 0.2$ & $3.6 \pm 0.3$ & $10.5 \pm 1.6$ \\
\hline
\end{tabular}


Table 2

Particle size of the EGSB effluent samples $(\mu \mathrm{m})$.

\begin{tabular}{lllll}
\hline & Average particle size & $d(0.1)$ & $d(0.5)$ & $d(0.9)$ \\
\hline S1 & 280.5 & 10.3 & 171.5 & 711.8 \\
S2 & 228.8 & 21.8 & 184.7 & 499.1
\end{tabular}

(A)

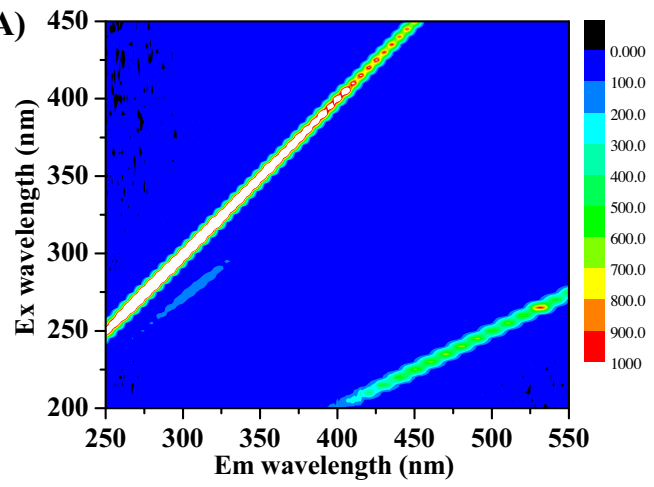

(B)

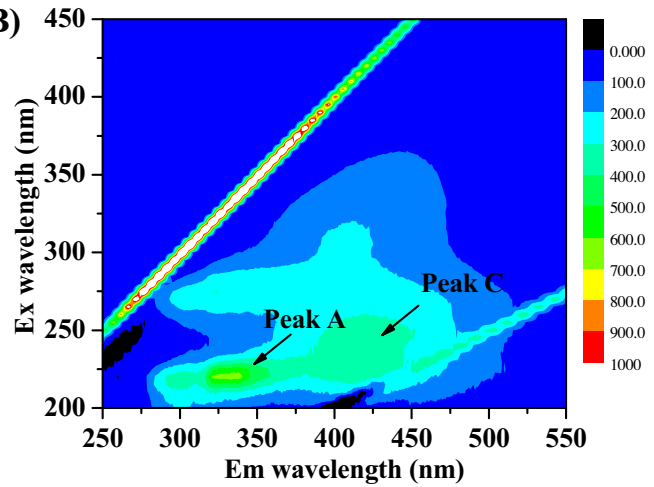

(C)

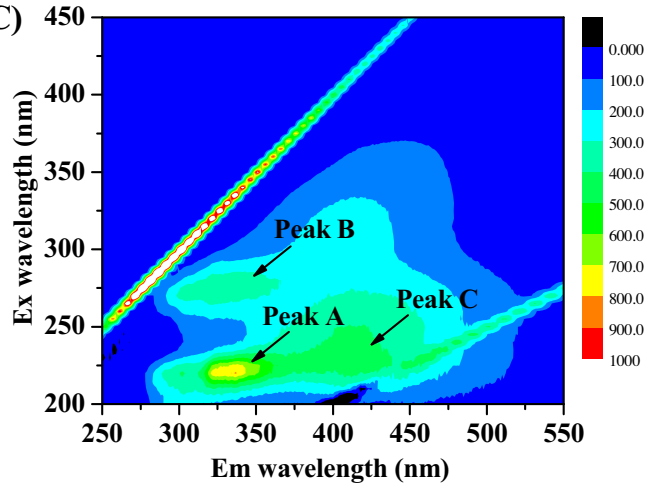

Fig. 2. Effect of GAC addition on the EEM fluorescence spectra of EGSB effluents: (A) feed water; (B) EGSB1 effluent: S1; (C) EGSB2 effluent: S2.

Table 3

Fluorescence spectral parameters of effluent samples.

\begin{tabular}{|c|c|c|c|c|c|c|}
\hline \multirow[t]{2}{*}{ Sample } & \multicolumn{2}{|l|}{ Peak A } & \multicolumn{2}{|l|}{ Peak B } & \multicolumn{2}{|l|}{ PeakC } \\
\hline & $\mathrm{Ex} / \mathrm{Em}$ & Intensity & $\mathrm{Ex} / \mathrm{Em}$ & Intensity & $\mathrm{Ex} / \mathrm{Em}$ & Intensity \\
\hline S1 & $220 / 333$ & 617.2 & - & - & $230 / 416$ & 385.0 \\
\hline S2 & $220 / 334$ & 737.4 & $275 / 305$ & 425.6 & $230 / 404$ & 539.0 \\
\hline
\end{tabular}

(Ex/Em) of 235-240/340-355 nm (Peak A), which was associated with the simple aromatic proteins such as tyrosine (Baker, 2001; Chen et al., 2003). The second main peak was at the Ex/Em of 275-280/320-330 nm (Peak B), which was related to the trypto- phan protein-like substances (Baker, 2001; Chen et al., 2003). The third peak at the Ex/Em of 240-260/390-445 nm (Peak C) was described as the fluorescence of fulvic-like substances (Pons et al., 2004), while the fourth peak (around the Ex/Em of 290$350 / 410-435 \mathrm{~nm}$ (Peak D)) was identified as a visible humic acid-like fluorophores (Chen et al., 2003).

As seen in Fig. 2(A)-(C), there were no peaks in the feed solution, which indicated that the feed solution did not contain fluorescent substances. S1 and S2 contained both peaks A and C, representing the existence of aromatic protein-like substances and fulvic-like substances, respectively. There was no peak B appearing in S1 suggesting the absence of tryptophan protein-like substances. Therefore, these aromatic protein-like substances, tryptophan protein-like substances and fulvic-like substances were generated from the microbial metabolism after 3 month operation. Moreover, adding GAC could mainly reduce the tryptophan protein-like substances. With regard to the fluorescence peak intensity, the values of peak $A$ and peak $C$ of $S 1$ were both lower than those of S2. It demonstrated that GAC addition also decreased
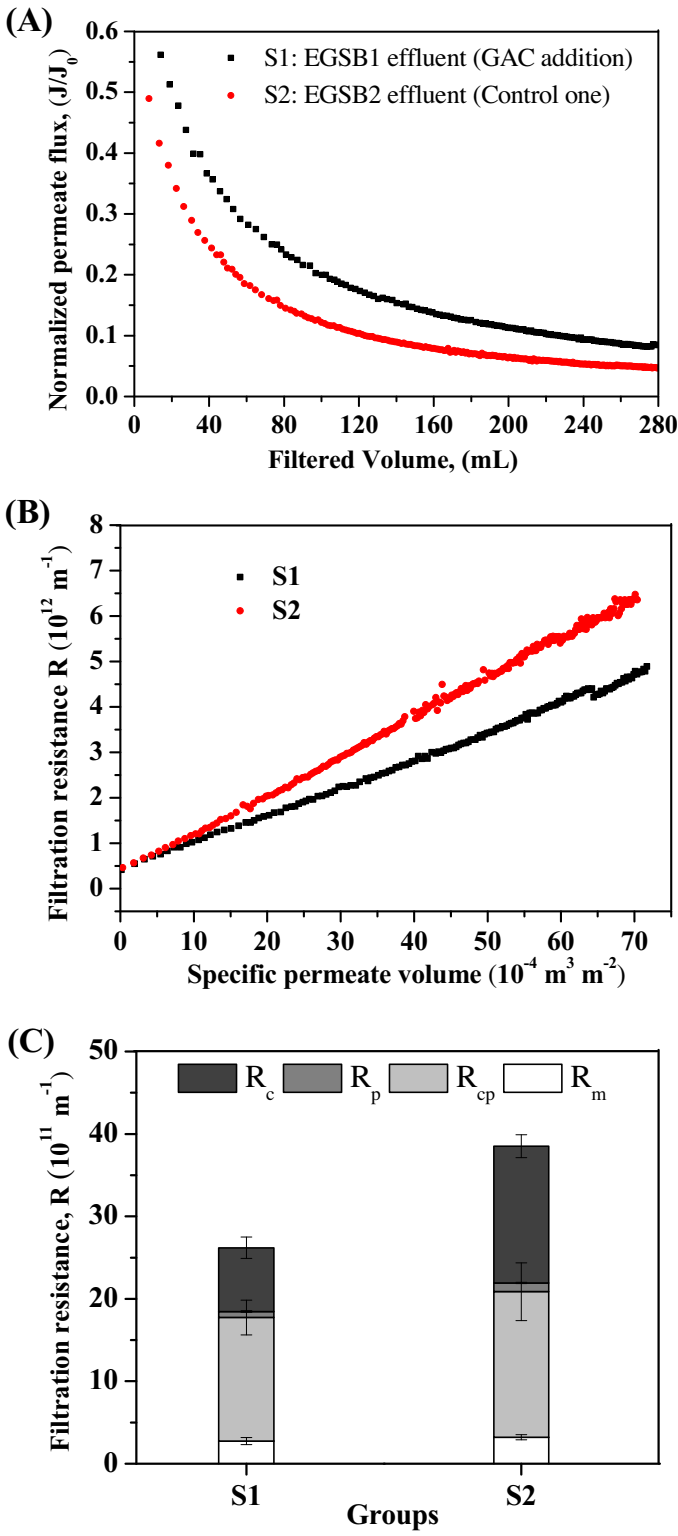

Fig. 3. Effect of GAC addition on the membrane fouling potential of EGSB effluents: (A) normalized flux declines; (B) the total filtration resistance variation of the effluents with the specific volumes; (C) total filtration resistance distributions. 

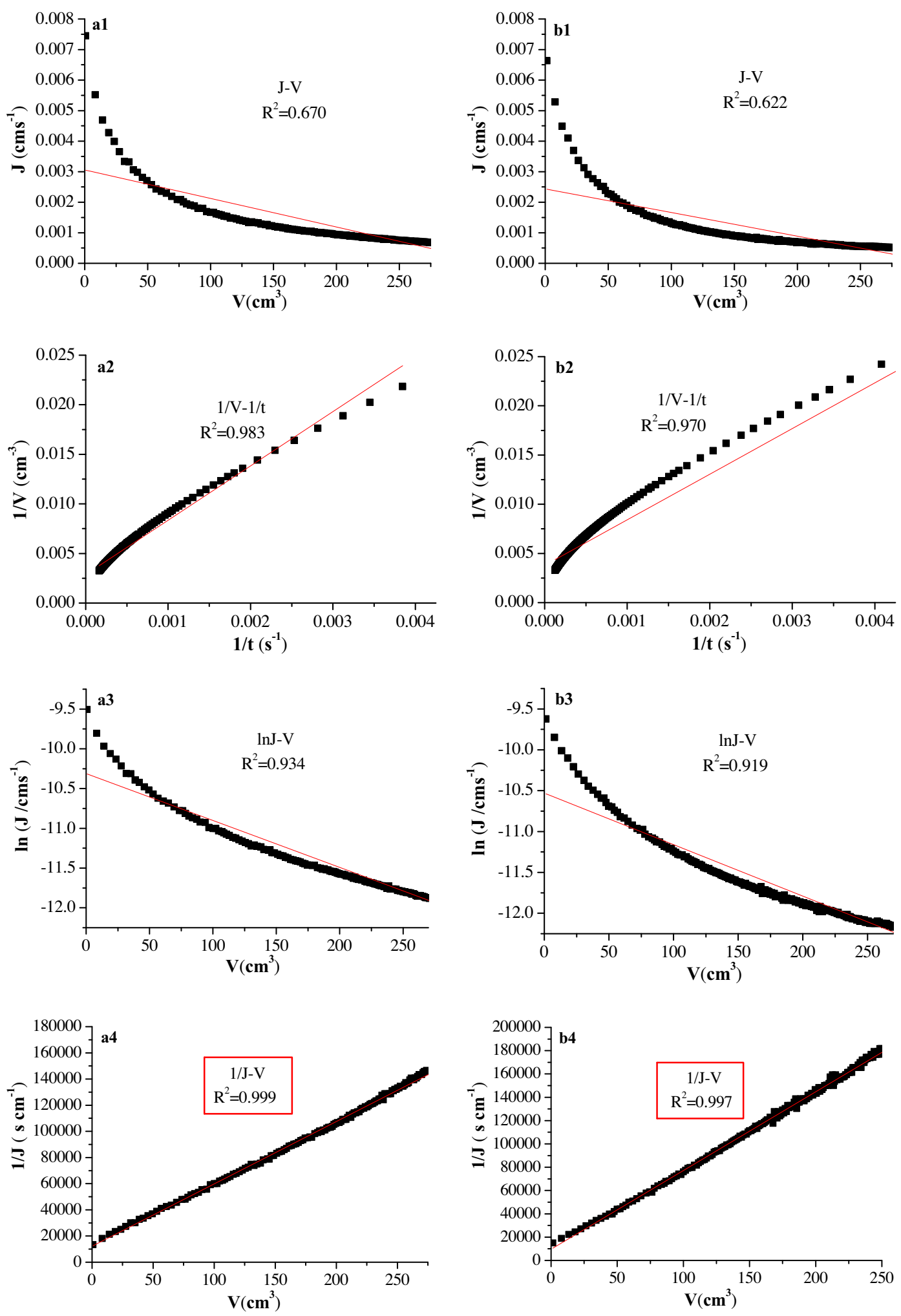

Fig. 4. Fitting the flux decline to the four fouling models (a: S1; b: S2): (1) complete blocking; (2) intermediate blocking; (3) standard blocking; and (4) cake filtration.

the concentrations of aromatic protein-like substances and fulviclike substances. Johir et al. (2011) compared the properties of SMP in a SMBR with GAC addition and a control SMBR. The effluent from both SMBRs had negligible organics, whereas SMP had organics of aminoacid type (Ex/Em: 200-250/330-380) and fulvic acid type substances (Ex/Em: 200-250/380-500). However, the peak inten- sities of the GAC addition sample were lower than the control one. As such, no matter in aerobic or anaerobic processes, GAC addition could help to reduce the aminoacid-like substances and fulvic-like substances. Overall, adding GAC in EGSB mainly reduced tryptophan protein-like substances, and following by aromatic protein-like substances and fulvic-like substances. 


\subsection{Effect of GAC addition on the UF membrane fouling potential}

\subsubsection{Flux decline}

A short-term dead-end UF system was applied to investigate the membrane fouling potential of membrane-coupled EGSB process. The feed solutions were collected from the effluents of two EGSBs during Day 75-80. Fig. 3(A) shows the flux decline tendencies of the effluent samples. The fluxes of both curves dropped rapidly in the first $60 \mathrm{~mL}$, and after this decreased slowly. The flux decline of S2 was more severe than S1. Similarly, Kim et al. (2010) also found that GAC addition reduced the TMP growth rate under a constant flux in an anaerobic fluidized bed membrane bioreactor. The results of flux decline are quite in line with the reduced concentrations of SMP in the effluents. Nevertheless, the GAC addition had less improvement on the turbidity (or suspended solid) of the effluent. Therefore, it can be concluded that the main reason for GAC mitigating membrane fouling was that it could improve COD removal and help to reduce SMP in the effluent, but not the suspended solid. Especially, GAC addition effectively reduced the tryptophan protein-like substances, and aromatic protein-like and fulvic-like substances came second.

\subsubsection{Fouling model and filtration resistance analyses}

Classic filtration models were applied to evaluate the fouling potential of EGSB effluents. The simple regression results of the 4 models are given in Fig. 4. The $R^{2}$ values of S1 and S2 were around 0.65 under complete blocking model (Fig. 4a1 and b1). The values were between 0.92 and 0.98 under standard blocking and intermediate blocking models (Fig. 4a2, b2, a3 and b3). However, they were both greater than 0.99 under the cake filtration model (Fig. 4a4 and b4), which elucidated that the primary fouling model of EGSB effluents was the cake filtration. The results above also indicated that the average particle size of the effluents was $200-300 \mu \mathrm{m}$, which was much larger than the pore size of the membrane $(0.01 \mu \mathrm{m})$. Hence, the SMP of the both effluents mainly contributed to the gel cake layer on the membrane surface. Some previous research also revealed that the cake layer formation were the main fouling mechanism in membrane-coupled anaerobic reactors or AnMBRs (Choo and Lee, 1996; Robles et al., 2013).

In addition, filtration resistances were analyzed to better understand the alleviation of membrane fouling by GAC addition. Fig. 3(B) shows the total resistance $\left(R_{t}\right)$ variation of S1 and S2 with the specific volume. The $R_{t}$ values of $\mathrm{S} 2$ were larger than $\mathrm{S} 1$ from the beginning to the end which coincides with the results of flux decline. Fig. 3(C) presents the resistance distribution of the two effluents at the end of the filtration. The $R_{t}$ of S1 and S2 were $26.2 \times 10^{11} \mathrm{~m}^{-1}$ and $38.5 \times 10^{11} \mathrm{~m}^{-1}$, respectively, indicating that GAC addition into EGSB reduced the $R_{t}$ by $32.0 \%$, compared to the control one (S2). The membrane resistance $\left(R_{m}\right)$ and pore blocking resistance $\left(R_{p}\right)$ for both effluent were almost the same, with the values of around $3.0 \times 10^{11} \mathrm{~m}^{-1}$ and $0.1 \times 10^{11} \mathrm{~m}^{-1}$, respectively. However, GAC addition into EGSB significantly decreased the cake layer resistance $\left(R_{c}\right)$ proportion by $53.5 \%$ and the values of $R_{c}$ of $\mathrm{S} 1$ and S2 were $7.7 \times 10^{11} \mathrm{~m}^{-1}$ and $16.6 \times 10^{11} \mathrm{~m}^{-1}$, respectively. Overall, adding GAC into EGSB could alleviate cake layer fouling whereas the main fouling mode of membrane-coupled EGSB process was cake layer filtration regardless of GAC addition.

Based on our experimental results, schematic illustration of membrane fouling mechanism of EGSB effluents for both EGSBs are proposed in Supplementary data. And this work may be useful to better understand the membrane fouling potential and develop a fouling control strategy during the membrane-coupled anaerobic process. Although the GAC addition has the potential of mitigating membrane fouling of membrane-coupled EGSB process, the studies on the long-term UF process will be conducted in our further study with the real domestic wastewater.

\section{Conclusion}

GAC addition improved the COD removal efficiency. It alleviated membrane fouling of the EGSB effluent. The reason was that GAC addition reduced the SMP, $\mathrm{SMP}_{\mathrm{ps}}$ and $\mathrm{SMP}_{\mathrm{pr}}$ by $26.8 \%, 27.8 \%$ and $24.7 \%$, respectively, but not suspended solids. EEM analyses revealed GAC primarily help to reduce the tryptophan protein-like substances, and aromatic protein-like and fulvic-like substances came second. Furthermore, resistance analysis demonstrated that GAC mainly decreased the $R_{c}$ with the reduction of $53.5 \%$. This work provided a useful fouling control strategy that a certain concentration GAC could be considered to add into anaerobic reactors during the membrane-coupled anaerobic process.

\section{Acknowledgements}

This work was support by the National Natural Science Foundation of China (51038003), the Funds for Creative Research Groups of China (51121062), Industry-University-Research Collaboration Project of Guangdong Province \& Chinese Ministry of Education (2012B091000029), Key Breakthrough Project of Guangdong \& Hong Kong (2012BZ100021) and Industry-University-Research Collaboration Project of Chancheng District (2012107101169).

\section{Appendix A. Supplementary data}

Supplementary data associated with this article can be found, in the online version, at http://dx.doi.org/10.1016/j.biortech.2014. 08.080 .

\section{References}

Baker, A., 2001. Fluorescence excitation-emission matrix characterization of some sewage-impacted rivers. Environ. Sci. Technol. 35 (5), 948-953.

Barker, D.J., Stuckey, D.C., 1999. A review of soluble microbial products (SMP) in wastewater treatment systems. Water Res. 33 (14), 3063-3082.

Chen, W., Westerhoff, P., Leenheer, J.A., Booksh, K., 2003. Fluorescence excitationemission matrix regional integration to quantify spectra for dissolved organic matter. Environ. Sci. Technol. 37 (24), 5701-5710.

Choo, K.H., Lee, C.H., 1996. Membrane fouling mechanisms in the membranecoupled anaerobic bioreactor. Water Res. 30 (8), 1771-1780.

DuBois, M., Gilles, K.A., Hamilton, J.K., Rebers, P.A., Smith, F., 1956. Colorimetric method for determination of sugars and related substances. Anal. Chem. 28 (3), 350-356.

Gao, D.-W., Hu, Q., Yao, C., Ren, N.-Q., 2014. Treatment of domestic wastewater by an integrated anaerobic fluidized-bed membrane bioreactor under moderate to low temperature conditions. Bioresour. Technol. 159, 193-198.

Guo, W., Ngo, H.H., Li, J., 2012. A mini-review on membrane fouling. Bioresour. Technol. 122, 27-34

Huang, X., Wei, C.-H., Yu, K.-C., 2008. Mechanism of membrane fouling control by suspended carriers in a submerged membrane bioreactor. J. Membr. Sci. 309 (1-2), 7-16.

Johir, M.A.H., Aryal, R., Vigneswaran, S., Kandasamy, J., Grasmick, A., 2011. Influence of supporting media in suspension on membrane fouling reduction in submerged membrane bioreactor (SMBR). J. Membr. Sci. 374 (1-2), 121-128.

Johir, M.A., Shanmuganathan, S., Vigneswaran, S., Kandasamy, J., 2013. Performance of submerged membrane bioreactor (SMBR) with and without the addition of the different particle sizes of GAC as suspended medium. Bioresour. Technol. $141,13-18$.

Kim, J., Kim, K., Ye, H., Lee, E., Shin, C., McCarty, P.L., Bae, J., 2010. Anaerobic fluidized bed membrane bioreactor for wastewater treatment. Environ. Sci. Technol. 45 (2), 576-581.

Li, X.-Y., Wang, X.-M., 2006. Modelling of membrane fouling in a submerged membrane bioreactor. J. Membr. Sci. 278 (1-2), 151-161.

Lin, H.J. Xie, K., Mahendran, B., Bagley, D.M., Leung, K.T., Liss, S.N., Liao, B.O. 2009. Sludge properties and their effects on membrane fouling in submerged anaerobic membrane bioreactors (SAnMBRs). Water Res. 43 (15), 3827-3837.

Liu, Y., Tay, J.H., 2004. State of the art of biogranulation technology for wastewater treatment. Biotechnol. Adv. 22 (7), 533-563.

Lowry, O.H., Rosebrough, N.J., Farr, A.L., Randall, R.J., 1951. Protein measurement with the Folin phenol reagent. J. Biol. Chem. 193 (1), 265-275.

Meng, F. Chae, S.R., Drews, A., Kraume, M., Shin, H.S., Yang, F., 2009. Recent advances in membrane bioreactors (MBRs): membrane fouling and membrane material. Water Res. 43 (6), 1489-1512.

Meng, F., Zhou, Z., Ni, B.J., Zheng, X., Huang, G., Jia, X., Li, S., Xiong, Y., Kraume, M., 2011. Characterization of the size-fractionated biomacromolecules: tracking their role and fate in a membrane bioreactor. Water Res. 45 (15), 4661-4671. 
Ozgun, H., Dereli, R.K., Ersahin, M.E., Kinaci, C., Spanjers, H., van Lier, J.B., 2013. A review of anaerobic membrane bioreactors for municipal wastewater treatment: integration options, limitations and expectations. Sep. Purif. Technol. 118, 89-104. Pons, M.N., Le Bonte, S., Potier, O., 2004. Spectral analysis and fingerprinting for biomedia characterisation. J. Biotechnol. 113 (1-3), 211-230.

Robles, A., Ruano, M.V., Ribes, J., Seco, A., Ferrer, J., 2013. A filtration model applied to submerged anaerobic MBRs (SAnMBRs). J. Membr. Sci. 444, 139-147.

Shen, Y., Zhao, W., Xiao, K., Huang, X., 2010. A systematic insight into fouling propensity of soluble microbial products in membrane bioreactors based on hydrophobic interaction and size exclusion. J. Membr. Sci. 346 (1), 187-193.
Stuckey, D.C., 2012. Recent developments in anaerobic membrane reactors. Bioresour. Technol. 122, 137-148.

Tiwari, M., Guha, S., Harendranath, C.S., Tripathi, S., 2006. Influence of extrinsic factors on granulation in UASB reactor. Appl. Microbiol. Biotechnol. 71 (2), 145154.

Wang, Y., Leslie, G.L., Waite, T.D., 2014. Impact of iron dosing of membrane bioreactors on membrane fouling. Chem. Eng. J. 252, 239-248.

Wei, C.-H., Huang, X., Wang, C.-W., Wen, X.-H., 2006. Effect of a suspended carrie on membrane fouling in a submerged membrane bioreactor. Water Sci. Technol. 53 (6), 211 